\title{
Influence of unbalanced voltages on the movement of metallic particle in a three phase common enclosure gas insulated busduct
}

\author{
G V NAGESH KUMAR ${ }^{1, *}, \mathrm{~J} \mathrm{AMARNATH}^{2}, \mathrm{~B} \mathrm{P} \mathrm{SINGH}^{3}$ and \\ D DEEPAK CHOWDARY ${ }^{4}$
}

${ }^{1}$ Department of Electrical and Electronics Engineering, Vignan's Institute of Information Technology, Visakhapatnam 530046

${ }^{2}$ Jawaharlal Nehru Technological University, Kukatpally, Hyderabad 500085

${ }^{3}$ St. Martin's Engineering College, Dulapally, Quthbullapur,

Secunderabad 500014

${ }^{4}$ Department of Electrical and Electronics Engineering, Vignan's Institute of

Engineering for Women, Visakhapatnam 530046

e-mail: gundavarapu_kumar@yahoo.com

MS received 29 July 2008; revised 20 June 2010; accepted 24 June 2010

\begin{abstract}
Sulphur Hexafluoride $\left(\mathrm{SF}_{6}\right)$ is generally found to be very sensitive to field perturbations such as those caused by conductor surface imperfections and by conducting particle contaminants. A study of CIGRE group suggests that $20 \%$ of failures in Gas Insulated Substations (GIS) is due to the existence of various metallic contaminations in the form of loose particles. The presence of contamination can therefore be a problem with gas-insulated substations operating at high fields. If the effects of these particles could be eliminated, then this would improve the reliability of compressed gas insulated substation. It would also offer the possibility of operating at higher fields to affect a potential reduction in the GIS size with subsequent savings in the cost of manufacture and installation. The purpose of this paper is to develop techniques, which will formulate the basic equations that will govern the movement of metallic particles like aluminum, silver and copper in a bus duct. Simulation is carried out on particle movement with balanced and unbalanced voltages and the results have been presented and analysed.
\end{abstract}

Keywords. Metallic particles; electric field effects; gas insulated substations.

\section{Introduction}

Demand for electrical power has become one of the major challenges faced by the developing countries. Considering the relatively low per capita power consumption, there is a constant need for power capacity addition and technological upgradation. In developing countries like

*For correspondence 
India most of the additional power has been met by conventional electrical sources. Hence, the emphasis has shifted towards improving the reliability of transmission and distribution systems and ensuring that the innovations are not harmful to the environment.

Rapid urbanization and overgrowing population is making the task of expanding transmission network very difficult due to right of way problem and limited space availability. In addition, conventional air insulated substations have many problems such as pollution by salt or dust, meteorological difficulties and safety. Hence, there is a need to replace the conventional transmission lines and substations with underground cable and gas insulated substation (GIS) to overcome the above problems. Due to its many advantages, most of the utilities and industrial units are opting for Gas Insulated Substation (Christophorou et al 1997). In this context, gas insulated substation (GIS) have found a broad range of applications in power systems for more than two decades because of their high reliability, easy maintenance and small ground space requirement.

In a gas insulated bus duct (GIB), all live parts are enclosed in compressed Sulphur Hexafluoride gas chambers, which are divided into a number of compartments or bays according to the layout or configuration of its several components. Basic components of the GIS bay are circuit breakers, disconnectors, earthing switches, bus ducts, current and voltage transformers. The inner live parts of GIS are supported by insulators called spacers, which are made of alumina filled epoxy material. The GIS enclosure forms an electrically integrated, grounded enclosure for the entire substation. Even though $\mathrm{SF}_{6}$ exhibits very high dielectric strength, the withstand voltage of $\mathrm{SF}_{6}$ within the GIS is drastically reduced due to the presence of particles or defects like:

(i) Free particles on the inner surface of the enclosure, (ii) protrusion on the high voltage (HV) bus, (iii) protrusion on the inner surface of the enclosure and (iv) narrow gaps between the spacer and the electrode due to imperfect casting and or imperfect mechanical strength, which may lead to high electrical stress and thus micro discharges.

Free conducting particles are most dangerous to GIS. These free conducting particles may have any shape or size, may be spherical or filamentary (wire like) or in the form of fine dust. Particles may be free to move or may be fixed on to the surfaces. They may be of conducting material or of insulating material. Particles of insulating materials are not so harmful as they have little effect on the insulating properties of gases. So wire like particles made of conducting material are more harmful and their effects are more pronounced at higher gas pressures. The origin of these particles may be from the manufacturing process, from mechanical vibrations or from moving parts of the system like breakers or disconnectors.

Several workers conducted experiments on insulating particles (Christophorou et al 1997; Prakash et al 1997; Felic 1996). However, the presence of atmospheric dust containing conducting particles, especially on the cathode, reduces the breakdown voltage. Conducting particles placed in a uniform ac field lift-off at a certain voltage. As the voltage is raised, the particles assume a bouncing state reaching a height determined by the applied voltage. With a further increase in voltage, the bounce height and the corona current increase until break down occurs. The lift-off voltage is independent of the pressure of gas. After the onset of bouncing, the offset voltage is approximately $30 \%$ lower than the lift-off voltage.

Some of the methods of conducting particle control and de-activation are:

- Electrostatic trapping

- Use of adhesive coatings to immobilize the particles

- Discharging of conducting particles through radiation

- Coating conducting particles with insulating films. 


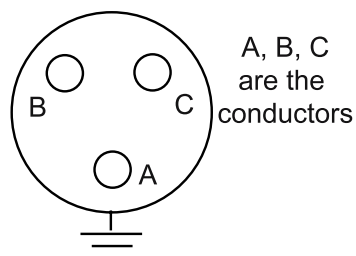

Figure 1. A typical 3-phase common enclosure gas insulated bus duct.

The work reported in this paper deals with the movement of metallic particle in 3 -phase common enclosure gas insulated busduct in a common enclosure with balanced and unbalanced voltages. In order to determine the axial and radial movement in an enclosure, Monte-Carlo technique has been adopted in conjunction with motion equation. The specific work reported deals with the charge acquired by the particle due to macroscopic field at the tip of the particle, the force exerted by the field i.e. electric field on the particle, drag due to viscosity of the gas and random behaviour during the movement. Wire like particles of aluminum, silver and copper of a fixed geometry in a 3-phase bus duct have been considered. The movement pattern for higher voltages class has also been obtained (Anis \& Srivastava 1989). In Monte-Carlo technique (Nagesh Kumar et al 2007) it has been assumed that at every time step the particle can have a maximum movement in a solid angle of $1^{\circ}$ to $4^{\circ}$ from vertical.

\section{Modelling technique}

A typical horizontal three-phase bus duct shown in figure 1 has been considered for the analysis.

Understanding the dynamics of a metallic particle in a coaxial electrode system is of vital importance for determining the effect of metallic contamination in a gas insulated system (GIS). If the motion pattern of a metallic particle is known, the probability of particle crossing a coaxial gap and causing a flashover can be estimated. The lift-off field for a particle on the surface of an electrode can be estimated by solving the motion equation.

A conducting particle in motion in an external electric field will be subjected to a collective influence of several forces. The forces may be divided into:

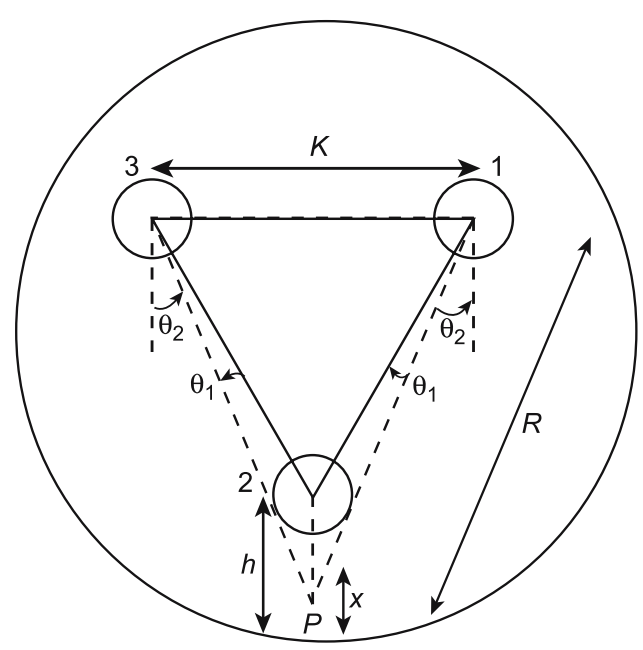

Figure 2. Schematic diagram of 3-phase common enclosure GIB. 
- Electrostatic force $\left(F_{e}\right)$

- Gravitational force $(\mathrm{mg})$

- Drag force $\left(F_{d}\right)$

The motion equation is given by

$$
\frac{m d^{2} y}{d t^{2}}=F_{e}-m g-F_{d}
$$

where $m=$ mass of the particle, $y=$ displacement in vertical direction, $F_{e}=$ Electrostatic force and $g=$ gravitational constant.

Figure 2 shows a horizontal three phase bus duct comprising of inner conductors spaced equilaterally in a metal enclosure. The enclosure is filled with $\mathrm{SF}_{6}$ gas at a high pressure $(0 \cdot 3 \mathrm{MPa})$. A particle is assumed to be at rest at the enclosure surface below bus bar 2, until a voltage sufficient enough to lift the particle and move in the field is applied.

After acquiring an appropriate charge in the field, the particle lifts and begins to move in the direction of field having overcome the forces due to its own weight and drag. The simulation considers several parameters e.g. the macroscopic field at the surface of the particle, its weight, Reynold's number, coefficient of restitution on its impact to both enclosures and viscosity of the gas. During return flight, a new charge on the particle is assigned based on the instantaneous electric field. The direction of drag force is always opposed to the direction of motion. The expression for drag Force and Electrostatic force given in equation (2) and equation (3).

$$
F_{d}=\dot{y} \pi r\left(6 \mu K_{d}(\dot{y})+2.656\left[\mu \rho_{g} l \dot{y}\right]^{0 \cdot 5}\right),
$$

where $\dot{y}$ is the velocity of the particle, $\mu$ is the viscosity of the fluid $r$ is the particle radius, $\rho_{g}$ is the gas density $l$ is the particle length, $K_{d}(\dot{y})$ is the drag coefficient.

The Electrostatic Force is given by

$$
F_{e}=\frac{\pi \epsilon_{0} l^{2} E\left(t_{0}\right)}{\ln \left(\frac{2 l}{r}\right)-1} \times 48.64 \times 10^{3}\left[\left(\frac{1}{0 \cdot 125-x}\right)-\left(\frac{\cos \theta_{2}}{R_{1}}\right)\right] \sin \omega t .
$$

The above forces are substituted in equation (1) and it becomes a second order nonlinear differential equation. To solve the motion equation Runge-Kutta 4th order method is adopted.

\section{Simulation of particle motion}

The study of the motion of moving metallic particles in GIS requires a good knowledge of the charge of the particle. Simulation of the motion of metallic particles were carried out on GIB of $64 \mathrm{~mm}$ inner diameter for each enclosure and $500 \mathrm{~mm}$ outer diameter with $400 \mathrm{kV} \mathrm{rms}$ line to line applied voltage to inner conductors with $120^{\circ}$ phase difference. Aluminum, Silver and copper wire like particles were considered to be present on enclosure surface. Simulation study also has been carried out on the same enclosure with unbalanced voltages with phase differences of $0^{\circ}, 150^{\circ}, 210^{\circ}$.

In order to determine the random behaviour of moving particles, the calculation of movement in axial and radial directions was carried at every time step using random numbers. The above simulation yields the particle movement in the radial direction only. However, the configuration at the tip of the particle is generally not sufficiently smooth enough to enable 


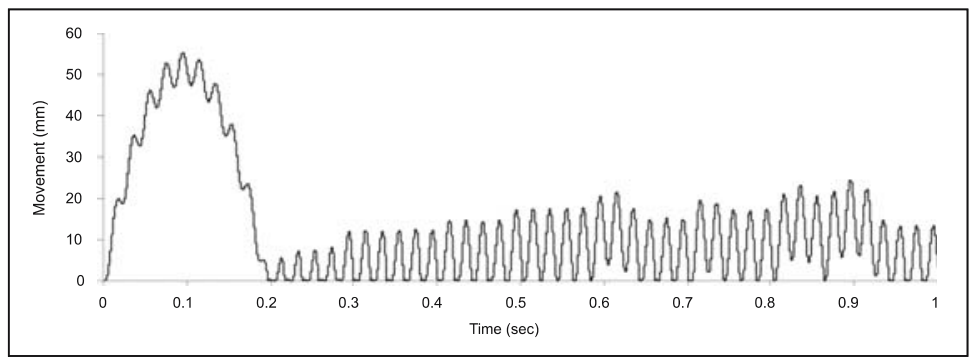

Figure 3. Particle movement with balanced voltages in a 3-Phase GIB for $500 \mathrm{kV} / \mathrm{Al} / \mathrm{length}=10 \mathrm{~mm} /$ radius $=0 \cdot 1 \mathrm{~mm}$.

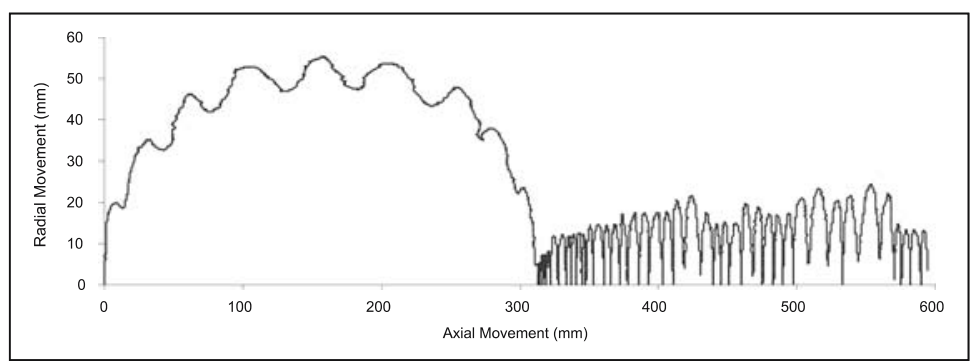

Figure 4. Axial and radial movement with balanced voltages in a 3-Phase in a GIB for $500 \mathrm{kV} / \mathrm{Al} / \mathrm{length}=10 \mathrm{~mm} / \mathrm{radius}=0 \cdot 1 \mathrm{~mm}$.

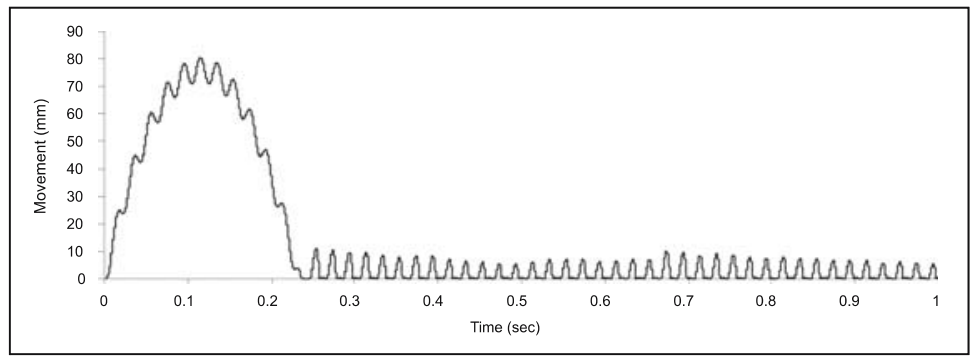

Figure 5. Particle movement with balanced voltages in a 3-Phase GIB for $600 \mathrm{kV} / \mathrm{Al} / \mathrm{length}=10 \mathrm{~mm} /$ radius $=0 \cdot 1 \mathrm{~mm}$.

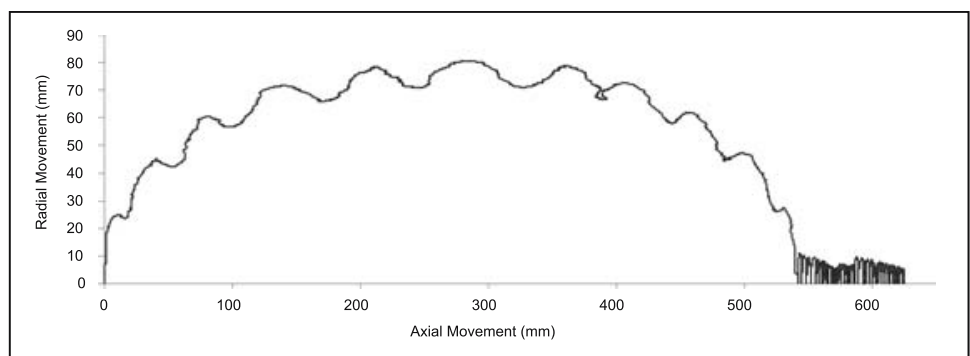

Figure 6. Axial and radial movement with balanced voltages in a 3-Phase in a GIB for $500 \mathrm{kV} / \mathrm{Al} /$ length $=10 \mathrm{~mm} / \mathrm{radius}=0.1 \mathrm{~mm}$. 


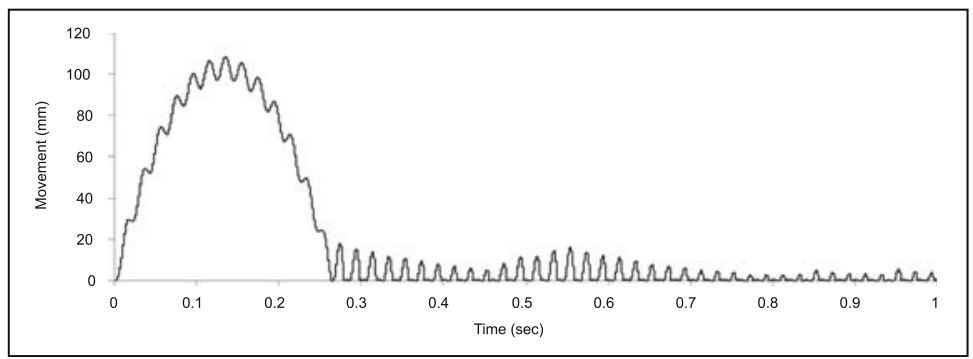

Figure 7. Particle movement with balanced voltages in a 3-Phase GIB for $700 \mathrm{kV} / \mathrm{Al} /$ length $=10 \mathrm{~mm} /$ radius $=0.1 \mathrm{~mm}$.

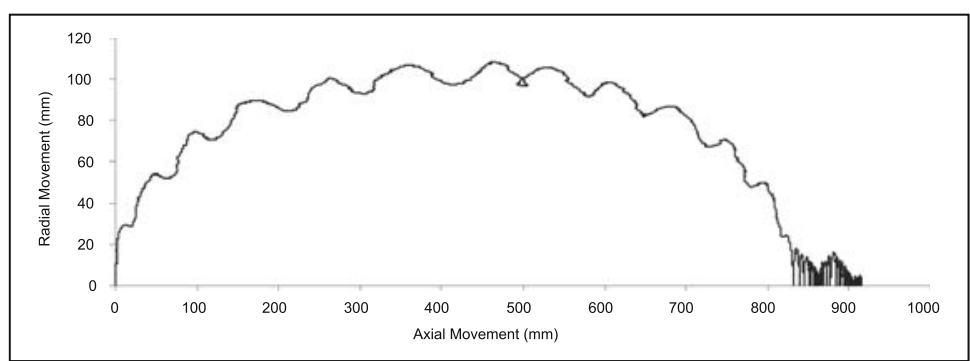

Figure 8. Axial and radial movement with balanced voltages in a 3-Phase GIB for $700 \mathrm{kV} / \mathrm{Al} / \mathrm{length}=10 \mathrm{~mm} / \mathrm{radius}=0 \cdot 1 \mathrm{~mm}$.

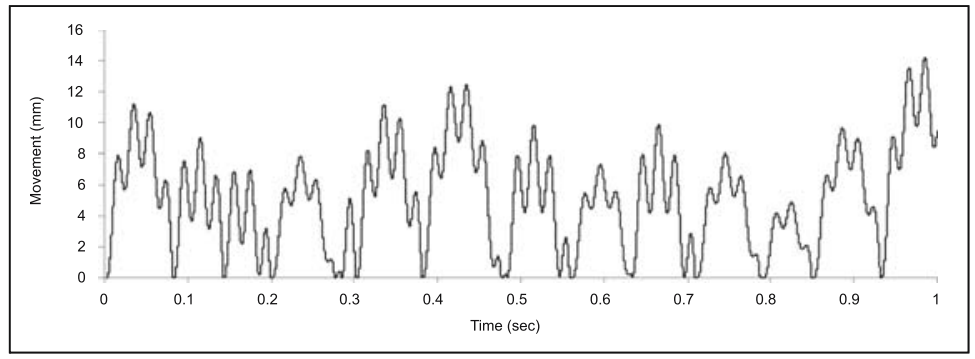

Figure 9. Particle movement with balanced voltages in a 3-Phase GIB for $500 \mathrm{kV} / \mathrm{Cu} /$ length $=10 \mathrm{~mm} /$ radius $=0 \cdot 1 \mathrm{~mm}$.

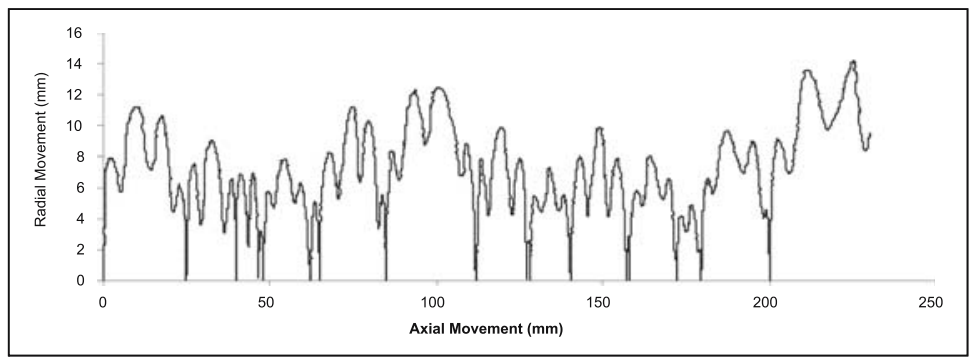

Figure 10. Axial and radial movement with balanced voltages in a 3-Phase GIB for $500 \mathrm{kV} / \mathrm{Cu} /$ length $=10 \mathrm{~mm} /$ radius $=0 \cdot 1 \mathrm{~mm}$. 


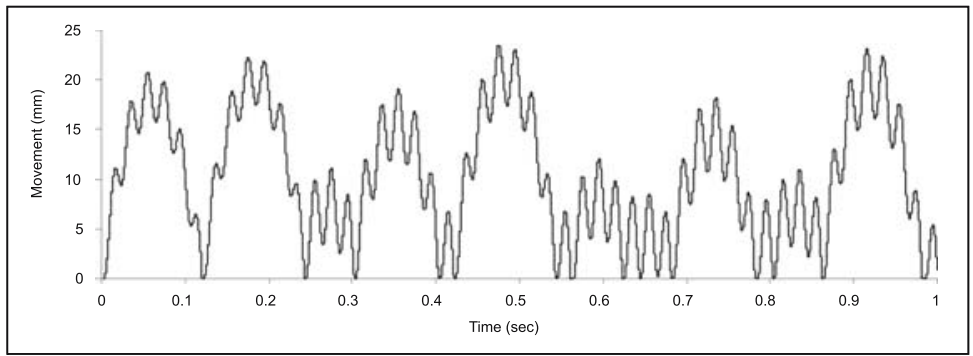

Figure 11. Particle movement with balanced voltages in a 3-Phase GIB for $600 \mathrm{kV} / \mathrm{Cu} /$ length $=10 \mathrm{~mm} /$ radius $=0 \cdot 1 \mathrm{~mm}$.

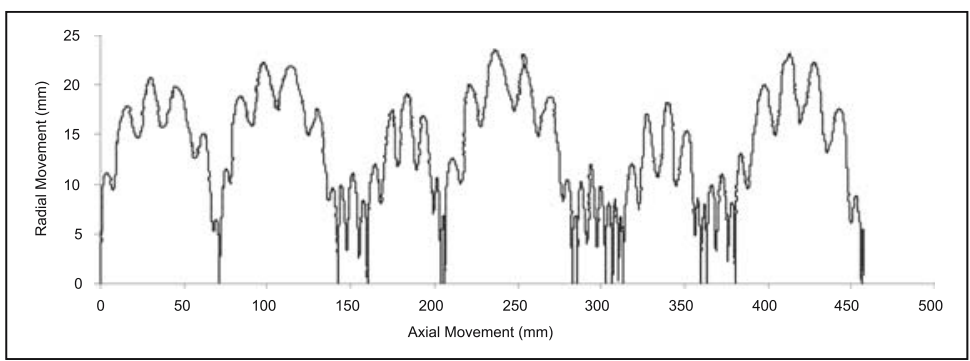

Figure 12. Axial and radial movement with balanced voltages in a 3-Phase GIB for $600 \mathrm{kV} / \mathrm{Cu} /$ length $=10 \mathrm{~mm} /$ radius $=0.1 \mathrm{~mm}$.

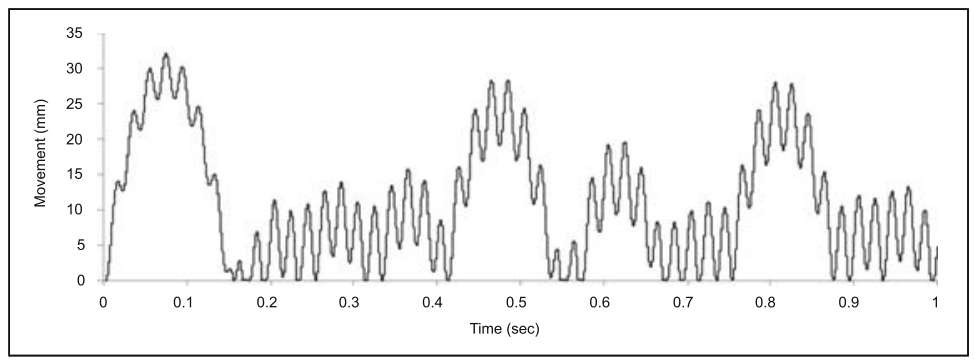

Figure 13. Particle movement with balanced voltages in a 3-Phase GIB for $700 \mathrm{kV} / \mathrm{Cu} /$ length $=10 \mathrm{~mm} /$ radius $=0.1 \mathrm{~mm}$.

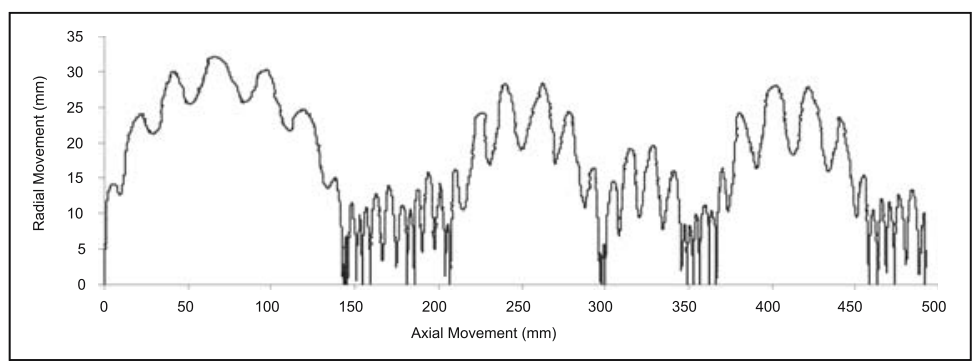

Figure 14. Axial and radial movement with balanced voltages in a 3-Phase GIB for $700 \mathrm{kV} / \mathrm{Cu} /$ length $=10 \mathrm{~mm} /$ radius $=0.1 \mathrm{~mm}$. 


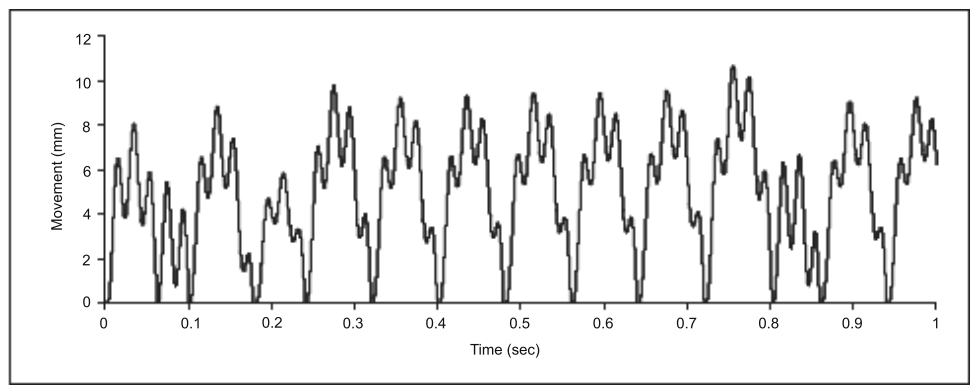

Figure 15. Particle movement with balanced voltages in a 3-Phase GIB for $500 \mathrm{kV} / \mathrm{Ag} / \mathrm{length}=10 \mathrm{~mm} / \mathrm{radius}=0 \cdot 1 \mathrm{~mm}$.

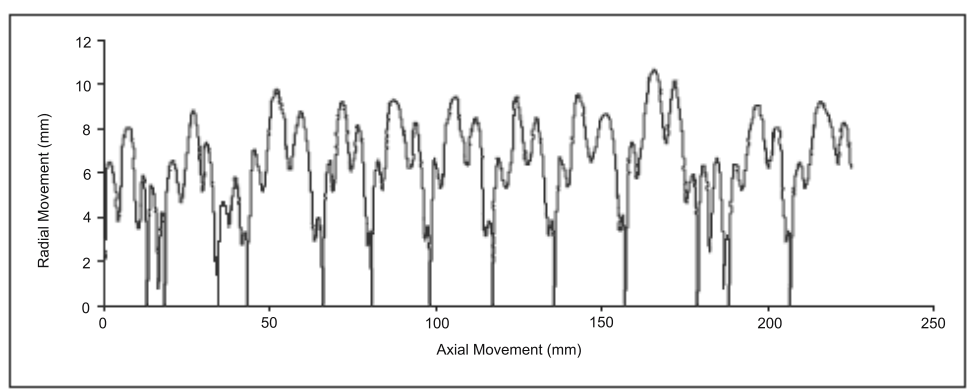

Figure 16. Axial and radial movement with balanced voltages in a 3-Phase GIB for $500 \mathrm{kV} / \mathrm{Ag} /$ length $=10 \mathrm{~mm} /$ radius $=0 \cdot 1 \mathrm{~mm}$.

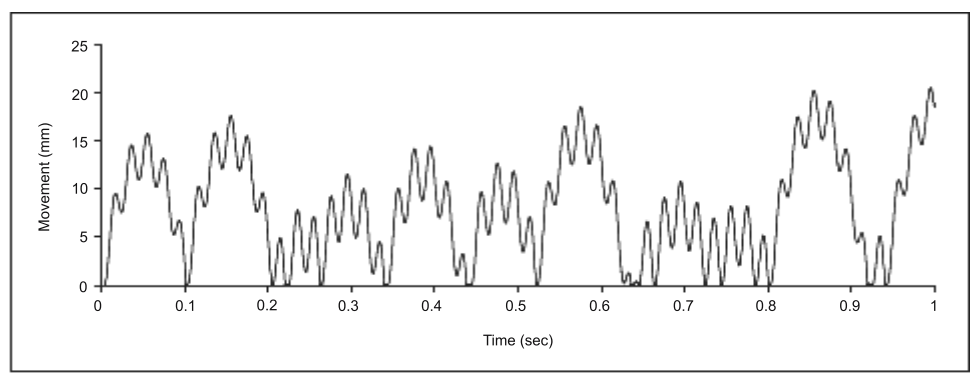

Figure 17. Particle movement with balanced voltages in a 3-Phase GIB for $600 \mathrm{kV} / \mathrm{Ag} / \mathrm{length}=10 \mathrm{~mm} /$ radius $=0 \cdot 1 \mathrm{~mm}$.

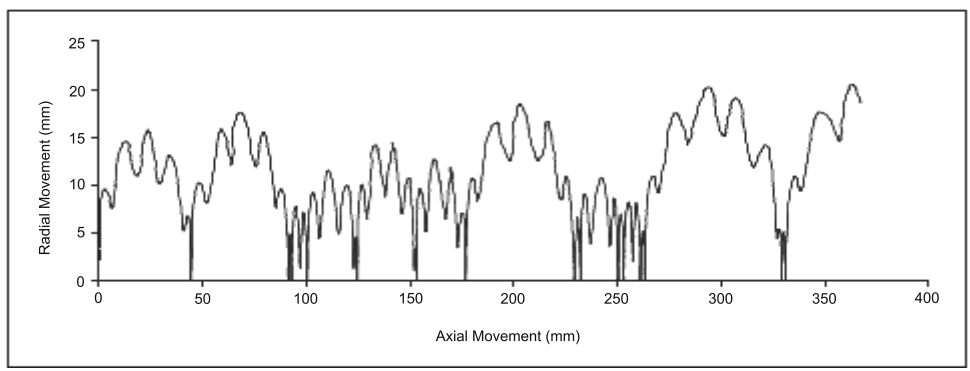

Figure 18. Axial and radial movement with balanced voltages in a 3-Phase GIB for $600 \mathrm{kV} / \mathrm{Ag} / \mathrm{length}=10 \mathrm{~mm} / \mathrm{radius}=0 \cdot 1 \mathrm{~mm}$. 
Table 1. Axial and radial movement of aluminum and copper particles with balanced voltages using Monte-Carlo technique.

\begin{tabular}{|c|c|c|c|c|}
\hline \multirow[b]{2}{*}{ Voltage } & \multirow[b]{2}{*}{ Type } & \multirow{2}{*}{$\begin{array}{c}\text { Max. radial } \\
\text { movement }(\mathrm{mm})\end{array}$} & \multicolumn{2}{|c|}{ Monte-Carlo $\left(1^{\circ}\right)$} \\
\hline & & & Axial (mm) & Radial (mm) \\
\hline \multirow[t]{3}{*}{$500 \mathrm{kV}$} & $\mathrm{Al}$ & 55.69 & $661 \cdot 12$ & 55.69 \\
\hline & $\mathrm{Cu}$ & 13.85 & $255 \cdot 70$ & 13.85 \\
\hline & $\mathrm{Ag}$ & $10 \cdot 65$ & $225 \cdot 24$ & $10 \cdot 65$ \\
\hline \multirow[t]{3}{*}{$600 \mathrm{kV}$} & $\mathrm{Al}$ & 80.57 & 1886.6 & 80.57 \\
\hline & $\mathrm{Cu}$ & 23.49 & 457.77 & 23.49 \\
\hline & $\mathrm{Ag}$ & $20 \cdot 469$ & $367 \cdot 33$ & 20.469 \\
\hline \multirow[t]{3}{*}{$700 \mathrm{kV}$} & $\mathrm{Al}$ & $108 \cdot 23$ & 915.43 & $108 \cdot 23$ \\
\hline & $\mathrm{Cu}$ & 32.03 & $492 \cdot 1$ & 32.03 \\
\hline & $\mathrm{Ag}$ & 25.90 & $472 \cdot 8$ & 25.9 \\
\hline
\end{tabular}

the movement unidirectional. This decides the movement of particle in axial direction. The randomness of movement can be adequately simulated by Monte-Carlo method. In order to determine the randomness, it is assumed that the particle emanates from its original site at any angle less than $\phi$, where $\phi / 2$ is half of the solid angle subtended with the vertical axis. At every step of movement, a new random number is generated between 0 and 1 and modified to $\phi$. The angle thus assigned, fixes the position of particle at the end of every time step, and in turn determines the axial and radial positions. The position in the next step is computed on the basis of equation of motion with new random angles as described above.

\section{Results and discussions}

Tables 1 and 2 show the radial and axial movement of the particle in a 3-Phase gas insulated bus duct with balanced and unbalanced voltages. The results have been presented by using

Table 2. Axial and radial movement of aluminum and copper particles with unbalanced voltages using Monte-Carlo technique.

\begin{tabular}{lcccc}
\hline & & Max. radial & \multicolumn{2}{c}{ Monte-Carlo $\left(1^{\circ}\right)$} \\
\cline { 4 - 5 } Voltage & Type & movement $(\mathrm{mm})$ & Axial $(\mathrm{mm})$ & Radial $(\mathrm{mm})$ \\
\hline $500 \mathrm{kV}$ & $\mathrm{Al}$ & 9.428 & $78 \cdot 82$ & $9 \cdot 428$ \\
& $\mathrm{Cu}$ & No movement & No movement & No movement \\
& $\mathrm{Ag}$ & No movement & No movement & No movement \\
$600 \mathrm{kV}$ & $\mathrm{Al}$ & $13 \cdot 56$ & $172 \cdot 95$ & $13 \cdot 56$ \\
& $\mathrm{Cu}$ & No movement & No movement & No movement \\
& $\mathrm{Ag}$ & No movement & No movement & No movement \\
$700 \mathrm{kV}$ & $\mathrm{Al}$ & $18 \cdot 57$ & $307 \cdot 96$ & $18 \cdot 57$ \\
& $\mathrm{Cu}$ & No movement & No movement & No movement \\
& $\mathrm{Ag}$ & No movement & No movement & No movement \\
\hline
\end{tabular}




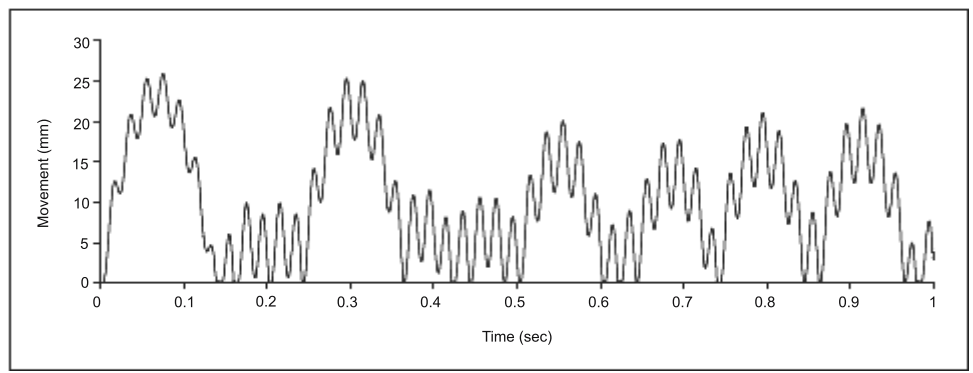

Figure 19. Particle movement with balanced voltages in a 3-Phase GIB for $700 \mathrm{kV} / \mathrm{Ag} / \mathrm{length}=10 \mathrm{~mm} /$ radius $=0.1 \mathrm{~mm}$.

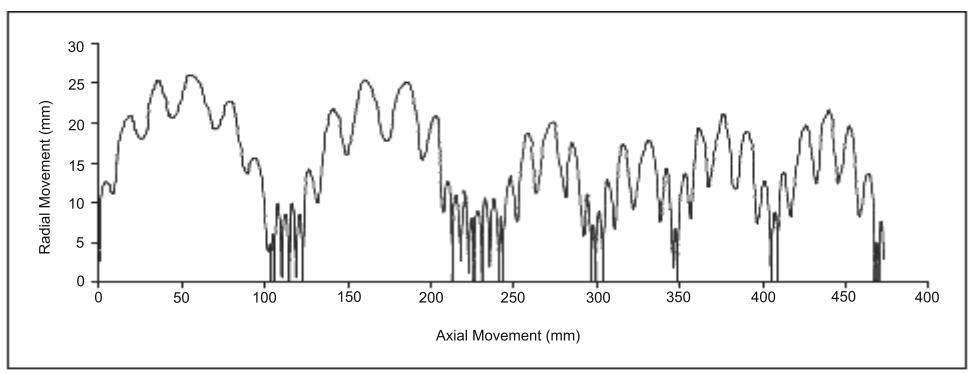

Figure 20. Axial and radial movement with balanced voltages in a 3-Phase GIB for $700 \mathrm{kV} / \mathrm{Ag} / \mathrm{length}=10 \mathrm{~mm} /$ radius $=0.1 \mathrm{~mm}$.

Monte-Carlo technique also shown in tables 1 and 2. Figures 3-20 show the movement patterns of Aluminum, copper and silver particles with balanced voltages and with MonteCarlo technique for different applied voltages. The radius of the particles in all cases is considered as $0.1 \mathrm{~mm}$ and length of the particle as $10 \mathrm{~mm}$. Voltages of equal magnitude but having a unequal phase difference is applied to the three conductors.

During its movement it makes several impacts with the enclosure. As the applied voltage increases the maximum radial movement also increases as given in table 1. Further increase in voltage may reveal the limiting voltage to enable the particle to reach the high voltage

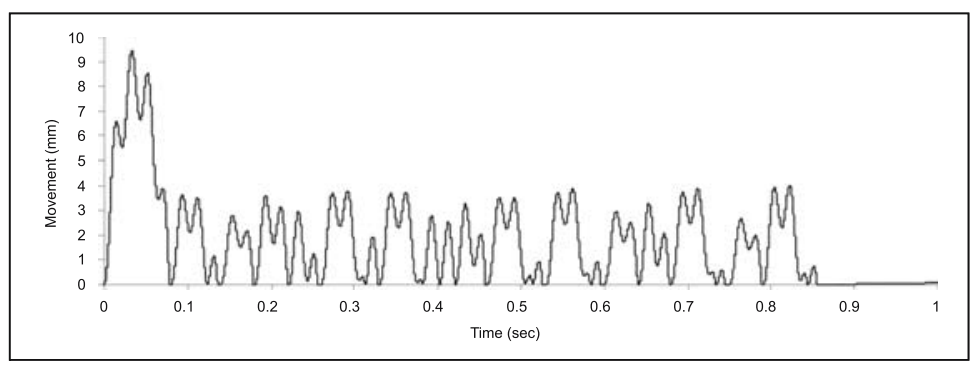

Figure 21. Particle movement with unbalanced voltages in a 3-Phase GIB for Al $/ 500 \mathrm{kV} /$ length $=10 \mathrm{~mm} /$ radius $=0 \cdot 1 \mathrm{~mm}$. 


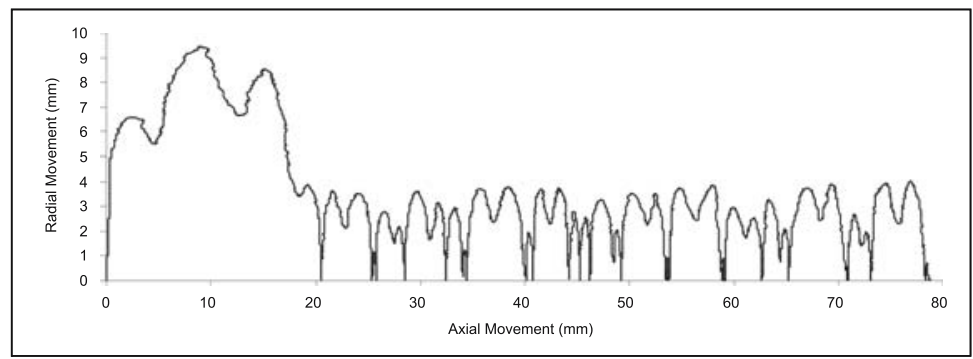

Figure 22. Axial and radial movement with unbalanced voltages in a 3-Phase GIB for $\mathrm{Al} / 500 \mathrm{kV} / \mathrm{length}=10 \mathrm{~mm} / \mathrm{radius}=0.1 \mathrm{~mm}$.

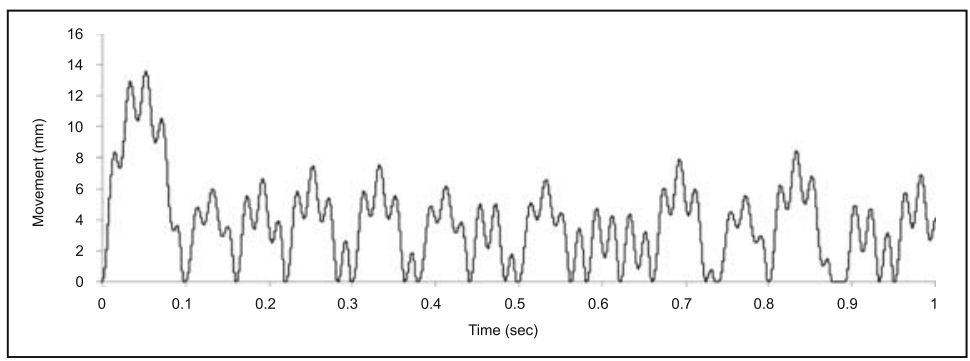

Figure 23. Particle movement with unbalanced voltages in a 3-Phase GIB for $\mathrm{Al} / 600 \mathrm{kV} /$ length $=10 \mathrm{~mm} / \mathrm{radius}=0.1 \mathrm{~mm}$.

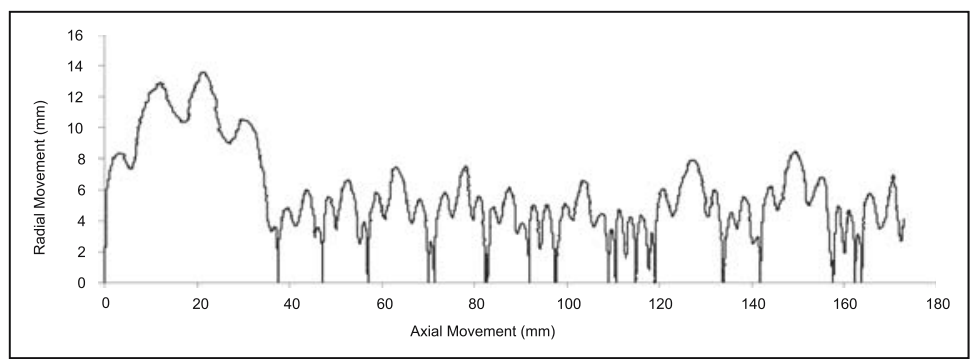

Figure 24. Axial and radial movement with unbalanced voltages in a 3-Phase GIB for $\mathrm{Al} / 600 \mathrm{kV} / \mathrm{length}=10 \mathrm{~mm} /$ radius $=0.1 \mathrm{~mm}$.

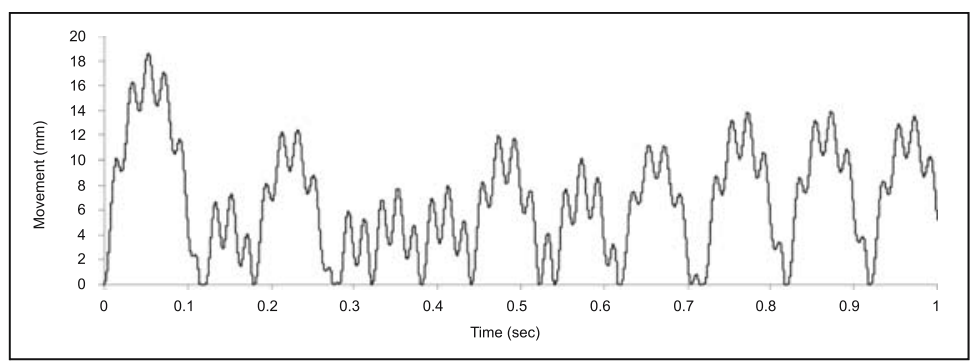

Figure 25. Particle movement with unbalanced voltages in a 3-Phase GIB for $\mathrm{Al} / 700 \mathrm{kV} /$ length $=10 \mathrm{~mm} / \mathrm{radius}=0 \cdot 1 \mathrm{~mm}$. 


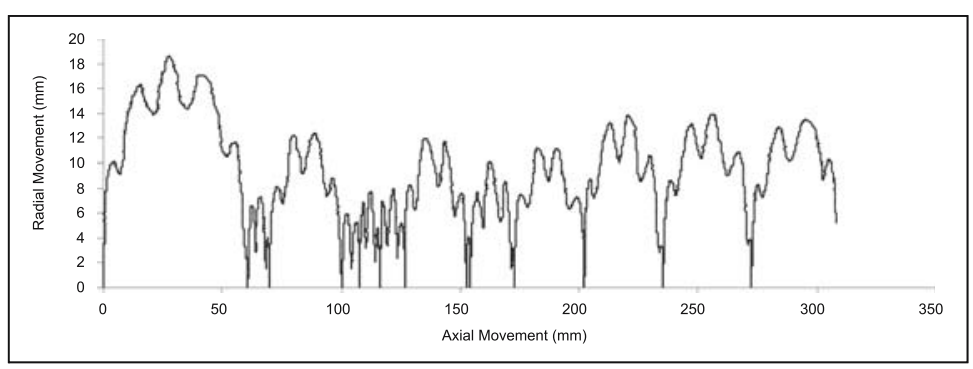

Figure 26. Axial and radial movement with unbalanced voltages in a 3-Phase GIB for $\mathrm{Al} / 700 \mathrm{kV} /$ length $=10 \mathrm{~mm} /$ radius $=0.1 \mathrm{~mm}$.

conductor. A graphical representation of radial movement in relation to axial movement is given by Monte-Carlo technique as shown in figure 4 . The movements are also calculated for other voltages. The movement of copper particle with balanced and unbalanced voltages is also given in tables 1 and 2. It is noticed that the movement of silver and copper particles are far less than aluminum particle of identical size. This is expected due to higher density of silver and copper particles. The axial and radial movement of aluminum, silver and copper particles are calculated using Monte-Carlo technique with a solid angle of $1^{\circ}$. The movement of aluminum, silver and copper particles with unbalanced voltages is shown in figures 20-26.

The effect of various parameters like radii and length of particles has been examined and presented in figures 27 and 28. Particles of radii varying from 0.01 to $0.1 \mathrm{~mm}$ and length from 1 to $10 \mathrm{~mm}$ have been used for simulation. Typical results show that for a variation of radii from 0.01 to $0.1 \mathrm{~mm}$ particles like aluminum, copper and silver, the maximum radial movement reduces as radii increases, whereas in the case of variation of length from 1 to $10 \mathrm{~mm}$ the radial movement increases for aluminum, copper and silver particles. As the radius

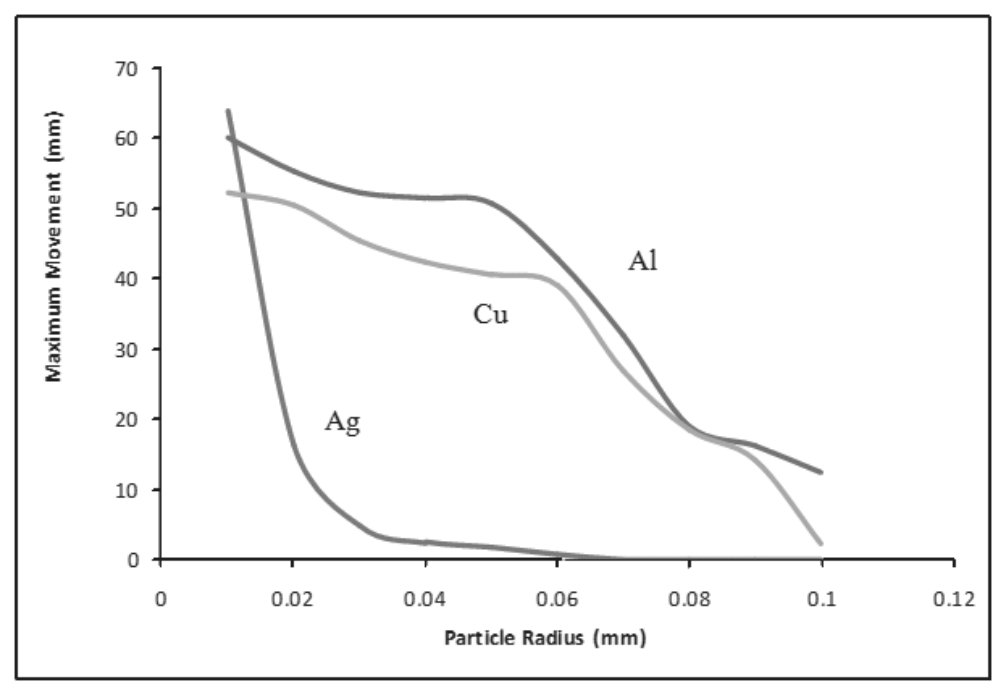

Figure 27. Movement of particle with variation of particle radius. 


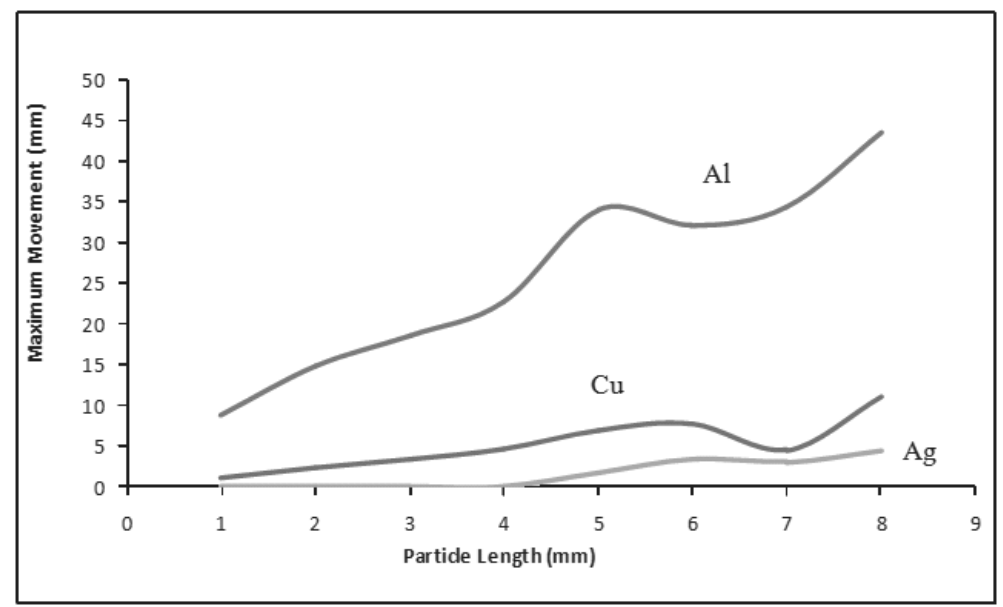

Figure 28. Movement of particle with variation of particle length.

increases, the maximum movement for any type of particle decreases. This nature is expected as explained earlier since the charge acquired is proportional to the logarithm of radius, where as mass is proportional to the square of the radius. The effect of variation is more predominant for aluminium particles as compared to those of silver and copper. The movement pattern with increase in the length of the particle is carried out and an entirely opposite pattern of movement is observed for the increasing length of particle as compared to increase in the radius. This is also true, since the charge which influences the movement of a particle, is proportional to the square of the particle length whereas the retarding force is proportional to the length only. As there is no movement for copper there will be no movement for silver particle.

\section{Conclusion}

A model has been formulated to simulate the movement of wire like particle in 3-phase common enclosure GIB on bare electrode. When electrostatic force exceeds the gravitational and drag forces the particle lifts from its position. A further increase in the applied voltage makes the particle move into the inter electrode gap in the direction of applied field. This increases the probability of a flashover. The influence of increased voltage level on the motion of the particles is also investigated and observed that the particle will lift higher from the surface. It is also observed that aluminum particles are more influenced by the voltage than copper or silver particles due to their lighter mass. This results in the aluminum particle acquiring greater charge-to-mass ratio.

Generally, the system always will not be in balanced condition. So it is required to estimate the particle movement under unbalanced voltage conditions also. In this paper, unbalanced load conditions have been studied and results were presented and analysed. It has been observed from tables 1 and 2 that under these conditions the movement will be less when compared to balanced load conditions. This is expected due to resultant electric field under unbalanced conditions is very much reduced so that movement is also decreased. MonteCarlo simulation is also adopted to determine axial as well as radial movements of particle in 
the bus duct. All the above investigations have been carried out for balanced and unbalanced voltages under power frequency.

The authors are thankful to the management of Jawaharlal Nehru Technical University (JNTU), Hyderabad and Vignan's Institute of Information Technology, Visakhapatnam for providing facilities and permission to publish this work.

\section{References}

Anis H and Srivastava K D 1989 Breakdown characteristics of dielectric coated electrodes in sulphur hexafluoride gas with particle contamination. Sixth International Symposium on High Voltage Engineering Paper No. 32.06, New Orleans, LA, USA

Christophorou L G, Olthoff J K, Van Brunt R J $1997 \mathrm{SF}_{6}$ and the electric power industry. IEEE Electrical Insulation Magazine DEIS 20-24

Felici N J 1966 Forces et charges de petits objects en contact avec une electrode affectee d'un champ electrique. Revue generale de I' electricite 1145-1160

Nagesh Kumar G V, Amarnath J, Singh B P, Srivastava K D 2007 Electric field effect on metallic particle contamination in a common enclosure gas insulated bus duct. IEEE Transactions on Dielectrics and Electrical Insulation 14(2): 334-340

Prakash K S, Srivastava K D, Morcos M M 1997 Movement of particles in compressed SF 6 GIS with dielectric coated enclosure. IEEE Transactions on Dielectrics and Electrical Insulation 4: 344-347 